\title{
Synthesis and Antimicrobial Activity of $\mathrm{N}$-(6-Carboxyl Cyclohex-3-ene Carbonyl) Chitosan with Different Degrees of Substitution
}

\author{
Mohamed E. I. Badawy ${ }^{1}$ and Entsar I. Rabea ${ }^{2}$ \\ ${ }^{1}$ Department of Pesticide Chemistry and Technology, Faculty of Agriculture, Alexandria University, El-Shatby, Alexandria 21545, Egypt \\ ${ }^{2}$ Department of Plant Protection, Faculty of Agriculture, Damanhour University, Damanhur 22516, Egypt \\ Correspondence should be addressed to Mohamed E. I. Badawy; m_eltaher@yahoo.com
}

Received 29 June 2016; Revised 15 September 2016; Accepted 28 September 2016

Academic Editor: Shin-ichiro Shoda

Copyright (C) 2016 M. E. I. Badawy and E. I. Rabea. This is an open access article distributed under the Creative Commons Attribution License, which permits unrestricted use, distribution, and reproduction in any medium, provided the original work is properly cited.

\begin{abstract}
Five products of $\mathrm{N}$-(6-carboxyl cyclohex-3-ene carbonyl) chitosan as antimicrobial agents were prepared by reaction of chitosan with tetrahydrophthalic anhydride (THPA) at different degrees of substitution (DS). The antimicrobial activity was evaluated against four plant bacteria and eight fungi. The results proved that the inhibitory property and water solubility of the synthesized chitosan derivatives, with increase of the DS, exhibited a remarkable improvement over chitosan. The product with a DS of 0.40 was the most active one with MIC of 510, 735, 240, and $385 \mathrm{mg} / \mathrm{L}$ against Erwinia carotovora, Ralstonia solanacearum, Rhodococcus fascians, and Rhizobium radiobacter, respectively, and also in mycelial growth inhibition against Alternaria alternata $\left(\mathrm{EC}_{50}=683 \mathrm{mg} / \mathrm{L}\right)$, Botrytis cinerea $\left(\mathrm{EC}_{50}=774 \mathrm{mg} / \mathrm{L}\right)$, Botryodiplodia theobromae $\left(\mathrm{EC}_{50}=501 \mathrm{mg} / \mathrm{L}\right)$, Fusarium oxysporum $\left(\mathrm{EC}_{50}=500 \mathrm{mg} / \mathrm{L}\right)$, F. solani $\left(\mathrm{EC}_{50}\right.$ $=260 \mathrm{mg} / \mathrm{L})$, Penicillium digitatum $\left(\mathrm{EC}_{50}=417 \mathrm{mg} / \mathrm{L}\right)$, Phytophthora infestans $\left(\mathrm{EC}_{50}=298 \mathrm{mg} / \mathrm{L}\right)$, and Sclerotinia sclerotiorum $\left(\mathrm{EC}_{50}\right.$ $=763 \mathrm{mg} / \mathrm{L}$ ). These compounds based on a biodegradable and biocompatible chitosan could be used as potentially antimicrobial agents in crop protection instead of hazardous synthetic pesticides.
\end{abstract}

\section{Introduction}

Chitosan is a linear biopolymer consists of higher than $70 \%$ of $\beta$-(1-4)-2-deoxy- $\beta$-D-glucopyranose (GlcN) and lower than $30 \%$ of $\beta$-(1-4)-2-acetamido-2-deoxy- $\beta$-D-glucose (GlcNAc) units linked by $\beta-1,4$-glucosidic bonds. It can be obtained through a deacetylation process of purified chitin, a naturally abundant polysaccharide, and the supporting material of crustaceans, insects, and fungi [1-3]. It has unique characteristics such as biocompatibility, biodegradability, and low toxicity to mammals and possesses reactive functional groups that make it useful in different areas of application related to agriculture [4-6], food industry and nutrition [7], biotechnology [8, 9], and biomedicine [10].

In agriculture, pre- and postharvest protection from different pathogens rely mainly on synthetic fertilizers and hazardous pesticides. Therefore, alternative solutions are needed due to concerns for public health, environmental protection, and development of resistant pests. Chitosan is widely used as a biocide either alone or blended with other natural products against plant pathogens that induce decay and harmful effects of the agricultural crops during the growing season and postharvest phase $[5,6,11-13]$. The antimicrobial activity of chitosan is coming from its polycationic nature and with chemical modification [5, 11, 12, 14, 15]. However, its low solubility at the $\mathrm{pH}$ higher than of 6.5 is the major limiting factor in its utilization, that is, its application in biology, since many enzyme assays are performed in neutral media. Therefore, the preparation of water-soluble chitosans could enhance its biological and physiological potential [5, $11,15,16]$. From the synthetic point, all of the chemical modifications have been performed on the primary amino group (at C-2) or the two hydroxyl groups (at C-3 and C6) of the chitosan molecule such as $\mathrm{N}$-reductive amination, quaternization, hydroxyalkylation, $\mathrm{N}, \mathrm{O}$-carboxymethylation, 
$\mathrm{N}, \mathrm{O}$-acylation, phosphorylation, $\mathrm{N}, \mathrm{O}$-phthaloylation, $\mathrm{N}, \mathrm{O}-$ succinylation, chitosan-amino acid and chitosan-peptide conjugates, and graft copolymerization [17-23]. Acylation of chitosan was the typical method involves reacting chitosan with either an acid chloride or acid anhydride forming $\mathrm{N}$-(acyl) chitosan, $\mathrm{O}$-(acyl) chitosan, $\mathrm{N}, \mathrm{O}$-(acyl), $\mathrm{N}$ (hydroxyacyl) chitosan, or $N$-(carboxyacyl) chitosan derivatives, but the reactions are not regioselective partly because of the heterogeneous reaction conditions [24-26].

$N$-(Carboxyacyl) chitosans were also prepared by reactions with intramolecular carboxylic anhydrides including maleic, glutaric, phthalic [27], and succinic [27, 28] anhydrides. On the other hand, $N$-(carboxyacyl) chitosans filaments were obtained by reaction of chitosan with carboxylic anhydrides in methanol at room temperature overnight [2931]. The products could be used in many kinds of application due to their solubility in wide range of the $\mathrm{pH}$ [32]. Badawy and Rabea synthesized $\mathrm{N}$-carboxyacyl chitosans at DS 0.090.86 by treatment of chitosan with glutaric anhydride at different mol ratios in a solution of $2 \%$ aqueous acetic acidmethanol $(1: 1, \mathrm{v} / \mathrm{v})$ and evaluated their antimicrobial activity against plant pathogens. As a result, $\mathrm{N}$-(4-carboxybutyroyl) chitosan derivatives ( $\mathrm{DS}=0.09,0.26,0.45,0.52$, and 0.86 ) were isolated at $80-93 \%$ yields [33].

Based on the current state of research and progress in corresponding areas, this article aims at preparing water-soluble $\mathrm{N}$-(6-carboxyl cyclohex-3-ene carbonyl) chitosan derivatives to enhance the antimicrobial activity of chitosan molecule against plant pathogenic bacteria Erwinia carotovora, Ralstonia solanacearum, Rhodococcus fascians, and Rhizobium radiobacter. In addition, the antifungal activity was tested against Alternaria alternata, Botrytis cinerea, Botryodiplodia theobromae, Fusarium oxysporum, Fusarium solani, Penicillium digitatum, Phytophthora infestans, and Sclerotinia sclerotiorum. The antimicrobial activities as MICs for bacteria and $\mathrm{EC}_{50} \mathrm{~s}$ for fungi were investigated and discussed in detail.

\section{Materials and Methods}

2.1. Chemicals and Reagents. Low molecular weight chitosan, tetrahydrophthalic anhydride (THPA), deuterium oxide, deuterated acetic acid, and 2,3,5,-triphenyltetrazolium chloride (TTC) were purchased from Sigma-Aldrich Co. (USA). Potato Dextrose Agar (PDA), Nutrient Broth (NB), and Nutrient Agar (NA) media were purchased from Oxoid Ltd. (Basingstoke, Hampshire, UK). NA was used to reactivate and propagate the tested bacteria. All materials were used without further purification.

2.2. Tested Microorganisms. Four plant pathogenic bacteria Erwinia carotovora, Ralstonia solanacearum, Rhodococcus fascians, and Rhizobium radiobacter were obtained from Microbiology Laboratory, Department of Plant Pathology, Faculty of Agriculture, Alexandria University, Egypt. Bacteria were maintained on NA medium at $37^{\circ} \mathrm{C}$. Eight plant pathogenic fungal strains Alternaria alternata (Family: Pleosporaceae, Class: Dothideomycetes), Botrytis cinerea (Family: Moniliaceae, Class: Deuteromycetes), Botryodiplodia theobromae (Family: Botryosphaeriaceae, Class: Dothideomycetes), Fusarium oxysporum (Family: Nectriaceae, Class: Sordariomycetes), F. solani (Family: Nectriaceae, Class: Sordariomycetes), Penicillium digitatum (Family: Trichocomaceae, Class: Eurotiomycetes), Phytophthora infestans (Family: Pythiaceae, Class: Oomycota), and Sclerotinia sclerotiorum (Family: Sclerotiniaceae, Class: Leotiomycetes) were provided by Microbiology Laboratory, Department of Plant Pathology, Faculty of Agriculture, Alexandria University, Alexandria, Egypt, and kept during the experiments on PDA medium at $27 \pm 2^{\circ} \mathrm{C}$.

2.3. Synthesis of N-(6-Carboxyl Cyclohex-3-ene Carbonyl) Chitosans. $\mathrm{N}$-(6-Carboxyl cyclohex-3-ene carbonyl) chitosan derivatives were synthesized according to the method of Hirano and Moriyasu [31] and the modification by Badawy and Rabea [33] as follows: A portion (1.7 g) of chitosan was dissolved in $50 \mathrm{~mL}$ of $2 \%$ aqueous acetic acid $(1 \%, \mathrm{v} / \mathrm{v})$, and the solution was diluted with methanol $(50 \mathrm{~mL})$. To this solution, THPA was added $(0.1,0.3,0.5,0.8$, and $1.0 \mathrm{~mol} /$ glucose amine (GlcN) unit). The mixture was stirred at $50^{\circ} \mathrm{C}$ for $5 \mathrm{~min}$ and kept at room temperature overnight. The mixture, which became in gel or solidified form, was washed with acetone to give pale yellow solid of $N$-(6-carboxyl cyclohex-3-ene carbonyl) chitosans (Figure 1).

2.4. NMR Spectroscopy. ${ }^{1} \mathrm{H}$ - and ${ }^{13} \mathrm{C}$-NMR measurements were performed on a JEOL A-500 NMR spectrometer (Faculty of Science, Alexandria University, Alexandria, Egypt) under a static magnetic field of $500 \mathrm{MHz}$ at $25^{\circ} \mathrm{C}$. Sample was introduced into $5 \mathrm{~mm} \Phi \mathrm{NMR}$ tube, to which $0.5 \mathrm{~mL}$ of $1 \%$ $\mathrm{CF}_{3} \mathrm{COOD} / \mathrm{D}_{2} \mathrm{O}$ solution was added, and finally the tube was kept at room temperature to dissolve the product.

\section{5. ${ }^{1} \mathrm{H}$ - and ${ }^{13} \mathrm{C}-\mathrm{NMR}$ Spectral Data}

\subsubsection{Spectral Data for Chitosan}

${ }^{1} \mathrm{H}$-NMR $\left(25^{\circ} \mathrm{C}\right) . \delta 2.09-2.12 \mathrm{ppm}$ (br s, $\left.\mathrm{NHCOCH}_{3}\right), 3.15-$ $3.30 \mathrm{ppm}$ (br m, H-2 of GlcN residue), 3.57-4.10 ppm (br m, $\mathrm{H}-3,4,5,6$ of GlcN unit and H-2,3,4,5,6 of GlcNAc unit), 4.88$5.00 \mathrm{ppm}$ (m, H-1 of GlcN and GlcNAc units).

${ }^{13} \mathrm{C}-\mathrm{NMR} \quad\left(25^{\circ} \mathrm{C}\right) . \delta 22.08 \mathrm{ppm} \quad\left(\mathrm{NH}(\mathrm{CO}) \mathrm{CH}_{3}\right), 56.59 \mathrm{ppm}$ (C-2), $61.02-61.28 \mathrm{ppm} \quad$ (C-6), $70.59-70.76 \mathrm{ppm}$ (C-3), 75.15-75.44 ppm (C-5), 77.78 ppm (C-4), 98.24 ppm (C-1), $174.79 \mathrm{ppm}\left(\underline{\mathrm{C}}(\mathrm{O}) \mathrm{CH}_{3}\right)$.

\subsubsection{Spectral Data for N-(6-Carboxyl Cyclohex-3-ene Car- bonyl) Chitosan Derivatives (Compounds 1-5)}

${ }^{1} H$-NMR. 2.01-2.11 ppm (br s, NHAc), 2.34-2.55 ppm (br, $2 \mathrm{CH}_{2}$ of cyclohex-3-enecarboxylic acid), 3.09-3.28 ppm (br $\mathrm{s}, \mathrm{H}-2$ of GlcN residue), 3.45-4.20 ppm (br m, $\mathrm{H}-2$ of GlcNAc and $\mathrm{H}-3,4,5,6$ of GlcN unit), 4.60-4.65 ppm (br s, H-1 of GlcNAc residue), $4.85-4.95 \mathrm{ppm}$ (br s, H-1 of GlcN residue), 5.75-5.77 ppm (s, $2 \mathrm{H}$ of cyclohex-3-enecarboxylic acid), and $11.50 \mathrm{ppm}$ (s, $\mathrm{H}$ of $\mathrm{COOH}$ of cyclohex-3-enecarboxylic acid). 


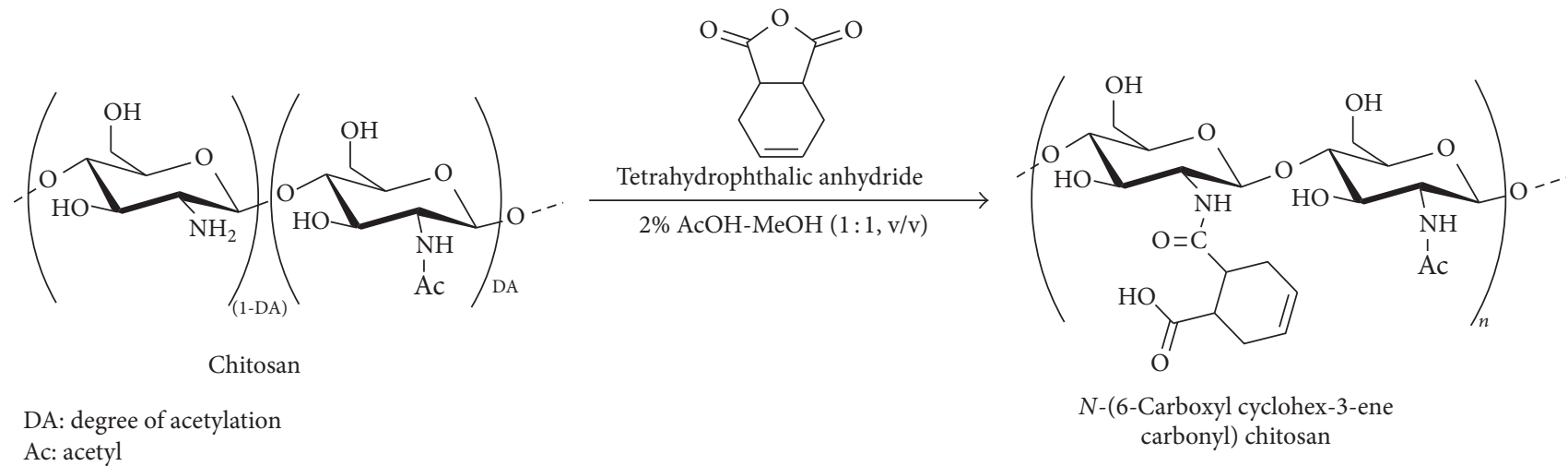

FIGURE 1: Reaction scheme of chitosan with tetrahydrophthalic anhydride at different mol ratios.

${ }^{13} \mathrm{C}-\mathrm{NMR}$. $\delta 20.51 \mathrm{ppm}\left(\mathrm{CH}_{2}(\beta)\right), 22.20\left(\mathrm{NH}(\mathrm{CO}) \mathrm{CH}_{3}\right)$, $25.35 \mathrm{ppm}\left(\mathrm{CH}_{2}-\mathrm{CH}_{2}\right.$ of cyclohex-3-ene), $39.50 \mathrm{ppm}(\mathrm{CH}-$ $\mathrm{CH}$ of cyclohex-3-ene), $55.92 \mathrm{ppm}$ (C-6), 60.10 (C-2), $70.19 \mathrm{ppm} \quad$ (C-3), $74.88 \mathrm{ppm} \quad$ (C-5), $76.54 \mathrm{ppm} \quad$ (C-4), 97.67 ppm (C-1), 125.28 ppm ( $\mathrm{HC}=\mathrm{CH}$ of cyclohex-3-ene), $176.23 \mathrm{ppm}\left(\mathrm{C}(\mathrm{O}) \mathrm{CH}_{3}\right), 177.89 \mathrm{ppm}(\mathrm{COOH}), 178.23 \mathrm{ppm}$ $(\mathrm{O}=\mathrm{C}-\mathrm{NH})$.

2.6. Average Molecular Weight $(M W)$. The average MWs of chitosan products were obtained from Mark-Houwink equation $\left(\eta=K M^{a}\right)[34,35]$, where $\eta$ is the intrinsic viscosity and $K$ and $a$ are viscometric parameters depending on the solvent. For a chitosan dissolved in $0.5 \mathrm{M} \mathrm{CH}_{3} \mathrm{COOH} / 0.2 \mathrm{M}$ $\mathrm{CH}_{3}$ COONa buffer, $\mathrm{K}$ and $a$ are found to be $3.5 \times 10^{-4}$ and 0.76 , respectively $[36,37]$. The viscosity of chitosan solution of different concentrations in acetate buffer $(\mathrm{pH}=5)$ was measured by using Ubbelohde Viscometer (capillary section size $0.7 \mathrm{~mm}$ ) immersed in a constant temperature bath at $25^{\circ} \mathrm{C}$ and having flow time for buffer solution, $T_{0}=53.65$ seconds. During preparation, all the solutions were magnetically stirred for $1 \mathrm{~h}$ to ensure proper dissolution of chitosan and were filtered using Whatman filter paper number 4 . The flow times of chitosan solutions and solvent were recorded in triplicate and the average value was calculated. The intrinsic viscosity $[\eta]$ was calculated graphically by extrapolating the curve of reduced viscosity versus chitosan concentration (g/dL) to zero concentration. The MW was then calculated by using Mark-Houwink equation.

2.7. Solubility Test. The solubility of chitosan and N-(6carboxyl cyclohex-3-ene carbonyl) chitosan products was performed in distilled water, aqueous acetic acid (0.1, 0.5 , and $1 \%, \mathrm{v} / \mathrm{v})$, and $1 \% \mathrm{NaOH}(\mathrm{w} / \mathrm{v})$. A sample was soaked in each solvent at the concentration of $10 \mathrm{mg} / \mathrm{mL}$ and the solubility was checked after standing for $24 \mathrm{~h}$ at room temperature [38].

\subsection{Antimicrobial Assay}

2.8.1. Antibacterial Activity. Nutrient Broth (NB) medium was used to grow the bacterial strains to a final inoculum size of $5 \times 10^{5} \mathrm{cfu} / \mathrm{mL}$ calculated as a number of colonies $x$ dilution factor/volume of culture plate using haemocytometer. Chitosan and its derivatives were dissolved in $0.5 \%$ aqueous acetic acid and added to the wells of a sterile 96well microtitre plate, followed by the addition of $140 \mu \mathrm{L}$ of NB medium and then $20 \mu \mathrm{L}$ of bacterial suspension. The final volume in each well was $200 \mu \mathrm{L}$ and the concentrations of $75,100,150,200,300,400,600,800,1000,1200$, and $1600 \mathrm{mg} / \mathrm{L}$ were tested for each compound. Control wells were prepared with culture medium, bacterial suspension only, and solvent. The contents of each well were mixed on a microplate shaker at $200 \mathrm{rpm}$ for $1 \mathrm{~min}$ prior to incubation for $24 \mathrm{~h}$ at $37^{\circ} \mathrm{C}$. To indicate respiratory activity the presence of color was determined after adding $10 \mu \mathrm{L} /$ well of TTC dissolved in water $(0.01 \%, \mathrm{w} / \mathrm{v})$ as a chromogenic marker and incubated under appropriate cultivation conditions for $30 \mathrm{~min}$ in the dark $[39,40]$. The absorbance was measured at $492 \mathrm{~nm}$ in an Ultra Microplate Reader (Robonik, PVT, LTD). Positive controls were wells with a medium and the compounds. Negative controls were wells with the growth medium, bacterial suspension, and the TTC reagent. The minimum inhibitory concentration (MIC) was determined as the lowest concentration where no viability was observed after $24 \mathrm{~h}$ based on metabolic activity. All measurements of MIC values were repeated in triplicate.

2.8.2. Antifungal Activity. The activity was tested using mycelia radial growth technique [41]. The compounds were dissolved as described in the antibacterial assay and serial concentrations of 250,500,1000,1500, 2000, 2500, and $3000 \mathrm{mg} / \mathrm{L}$ were tested. The aliquots of the stock solutions were added to the PDA medium and then transferred to Petri dishes. After solidification, the mixtures were inoculated with a $5 \mathrm{~mm}$ in diameter mycelium fungi at the center of Petri dishes and these were incubated in the dark at $27 \pm 2^{\circ} \mathrm{C}$. The fungal growth was measured when the control had grown to the edge of the plate. The inhibition of fungal growth was calculated as the percentage of inhibition of radial growth compared to the control. The effective concentration that inhibits $50 \%$ of mycelial growth $\left(\mathrm{EC}_{50}\right)$ for each compound was estimated by probit analysis [42] using of SPSS 21.0 software. 
TABLE 1: Chemical structure and properties of chitosan and its derivatives with tetrahydrophthalic anhydride [N-(6-carboxyl cyclohex-3-ene carbonyl) chitosan] at different mol ratios (see Scheme 1).

\begin{tabular}{|c|c|c|c|c|c|c|c|c|}
\hline Compound & $\begin{array}{c}\mathrm{THPA}^{\mathrm{a}} / \mathrm{mol} \\
\mathrm{GlcN}^{\mathrm{b}}\end{array}$ & $\mathrm{DA}^{\mathrm{c}}$ & $\mathrm{DDA}^{\mathrm{d}}$ & $\mathrm{DS}^{\mathrm{e}}$ & $\mathrm{FW}^{\mathrm{f}}$ & $\begin{array}{l}\text { Yield }^{\mathrm{h}} \\
(\%)\end{array}$ & $\begin{array}{c}\text { Intrinsic } \\
\text { viscosity }(\eta)\end{array}$ & $\begin{array}{c}\text { Average } \\
\mathrm{MW}^{\mathrm{g}}(\mathrm{Da}) \\
\times 10^{5}\end{array}$ \\
\hline Chitosan & - & 0.09 & 0.91 & - & 164.78 & - & 4.77 & 2.76 \\
\hline 1 & 0.1 & 0.07 & 0.84 & 0.09 & 177.27 & 84.79 & 5.09 & 3.01 \\
\hline 2 & 0.3 & 0.08 & 0.74 & 0.18 & 191.58 & 86.01 & 5.59 & 3.39 \\
\hline 3 & 0.5 & 0.06 & 0.68 & 0.26 & 203.63 & 94.86 & 6.18 & 3.87 \\
\hline 4 & 0.8 & 0.07 & 0.62 & 0.30 & 210.14 & 96.43 & 6.47 & 4.11 \\
\hline 5 & 1.0 & 0.06 & 0.54 & 0.40 & 224.70 & 97.11 & 7.20 & 4.74 \\
\hline
\end{tabular}

${ }^{\mathrm{a}} \mathrm{THPA}=$ tetrahydrophthalic anhydride. ${ }^{\mathrm{b}} \mathrm{GlcN}=$ glucosamine. ${ }^{\mathrm{c}} \mathrm{DA}$ is a degree of acetylation (calculated as $\left.1-\mathrm{DDA}\right) .{ }^{\mathrm{d}} \mathrm{DDA}$ is a degree of deacetylation. ${ }^{e} \mathrm{DS}$ is a degree of substitution. ${ }^{\mathrm{f}} \mathrm{FW}$ is a formula weight. ${ }^{\mathrm{g}} \mathrm{MW}$ is the molecular weight in $\mathrm{g} / \mathrm{mol}$ and it was determined for chitosan by measuring its intrinsic viscosity according to the Mark-Houwink-Sakurada equation and it was calculated for compounds $1-5$ as follows: ${ }^{\mathrm{h}}$ yield was determined by weight recovery in accordance with the change in FW.

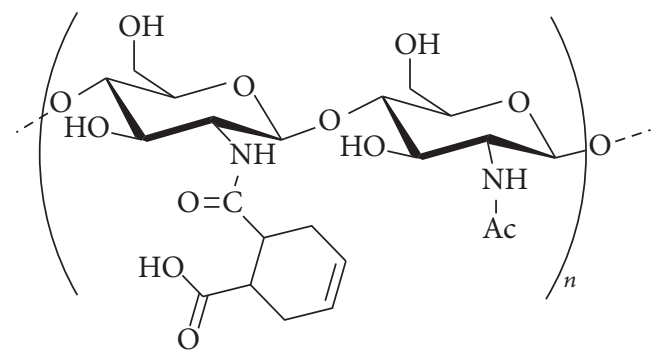

SCHEME 1

2.9. Statistical Analysis. Statistical analysis was performed using SPSS 21.0 software (Statistical Package for Social Sciences, USA). The log dose-response curves allowed determination of the $\mathrm{EC}_{50}$ values for the fungal bioassay according to the probit analysis [42]. The $95 \%$ confidence limits for the range of $\mathrm{EC}_{50}$ values were determined by the least-square regression analysis of the relative growth rate (\% control) against the logarithm of the compound concentration.

\section{Results and Discussion}

3.1. Characterization of N-(6-Carboxyl Cyclohex-3-ene Carbonyl) Chitosans. The chemical structure, degree of deacetylation (DDA), degree of substitution (DS), and formula weights (FW) were estimated by ${ }^{1} \mathrm{H}-\mathrm{NMR}$ spectra $[17,43]$ and the data are presented in Table 1 . Chitosan products were obtained at a range of DS $0.09-0.40$ when five mole ratios $(0.1,0.3,0.5,0.8$, and 1.0 mole) of THPA per glucose amine were tested. A hydrogel was produced in the reaction mixture with each product. The products of $\mathrm{N}$-(6-carboxyl cyclohex3 -ene carbonyl) chitosans were obtained with 84.79, 86.01, $94.86,96.43$, and $97.11 \%$ yield at DS of $0.09,0.18,0.26,0.30$, and 0.40 , respectively. Figure 2 shows the ${ }^{1} \mathrm{H}$ - and ${ }^{13} \mathrm{C}-\mathrm{NMR}$ spectra of chitosan and compound 5. The peak at $\delta 2.07-$ $2.12 \mathrm{ppm}$ is assigned to the proton of residual $\mathrm{CH}_{3}$ in acetyl group (Figures 2(a) and 2(b)). The peak at $\delta 3.09-3.30 \mathrm{ppm}$ is attributed to $\mathrm{H}-2$ of GlcN residue. The broad multiple peak at $\delta 3.49-4.15 \mathrm{ppm}$ is assigned for $\mathrm{H}-3,4,5,6$ of GlcN unit and
$\mathrm{H}-2,3,4,5,6$ of GlcNAc unit. The intense band at 4.8-5.30 ppm is related to $\mathrm{OH}$ groups and $\mathrm{HDO}$ (solvent). In this region, as observed more clearly from an extended spectrum, some different anomeric protons ( $\mathrm{H}-1$ of GlcN and GlcNAc units) appeared at $4.83-5.00 \mathrm{ppm}[24,44]$. Regarding product 5, the new peak at $\delta 2.35-2.50 \mathrm{ppm}$ represents the resonance of the two methylene groups of cyclohex-3-enecarboxylic acid; however the singlet peak at $\delta 5.74-5.82$ represents the two hydrogen protons of cyclohex-3-enecarboxylic acid and the new peak at $\delta 11.50 \mathrm{ppm}$ originated from the proton of $\mathrm{COOH}$ of cyclohex-3-enecarboxylic acid substituent (Figure 2(b)) confirming again the successful grafting of this substituent onto chitosan molecule at the amino group.

The DDA was calculated to be $91 \%$ in chitosan (Table 1) from the integral ratio between the proton on the C-2 and the GlcN unit protons. However, DDA of $N$-(6-carboxyl cyclohex-3-ene carbonyl) chitosans ranged from 0.54 to 0.84 . Determination of the DS value was based on the ratio between the areas of the protons in the substituent and the protons of the pyranose unit. The result proved that increasing the DS resulting in a decrease of the DDA that confirms the reaction mainly occurred on the amino group on C-2 of the GlcN. FW was calculated as follows: FW = $161 \times \mathrm{DDA}+203 \times \mathrm{DA}+\mathrm{MW}$ of $\mathrm{N}$-(6-carboxyl cyclohex3 -ene carbonyl) glucosamine unit $\times$ DS, where 161 and 203 are the FW of GlcN unit and GlcNAc, respectively. The results indicate that the FW was increased with the mol ratio increase. FW for chitosan, 1, 2, 3, 4, and 5 were 177.27, $191.58,203.63,210.14$, and 224.70, respectively, and the average molecular weight of the compounds ranged from 3.87 to $4.91 \times 10^{5} \mathrm{~g} / \mathrm{mol}$ (Table 1 ). The derivatives were reported to have average MW 3.01, 3.39, 3.87, 4.11, and $4.77 \times 10^{5} \mathrm{Da}$ compared to $2.76 \times 10^{5}$ for chitosan indicating that the MW is correlated with the intrinsic viscosity $(\eta)$.

Further evidence for confirmation the chemical structure was obtained from ${ }^{13} \mathrm{C}$-NMR spectroscopy. The carbon peaks due to $\mathrm{C}=\mathrm{O}$ and $\mathrm{CH}_{3}$ were found at 174.97 and $22.08 \mathrm{ppm}$ in chitosan, respectively. When we grafted THPA into the amino group of chitosan, new chemical shifts at 176.23, 177.89, and $178.23 \mathrm{ppm}$ appeared due to the resonance of the carbonyl group $(\mathrm{C}=\mathrm{O})$ present in the carboxyl group $(\mathrm{COOH})$ and 


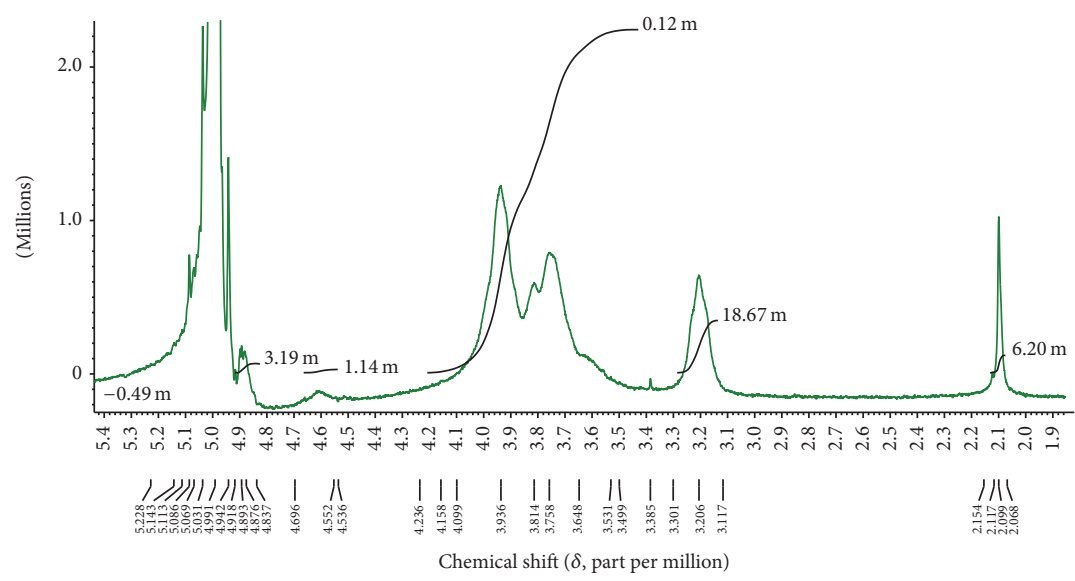

(a)

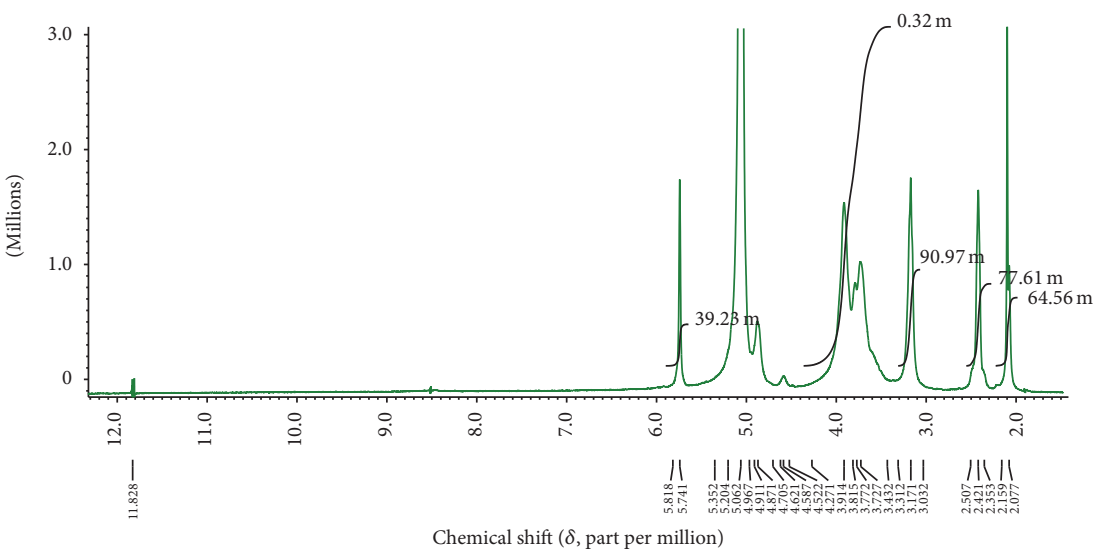

(b)

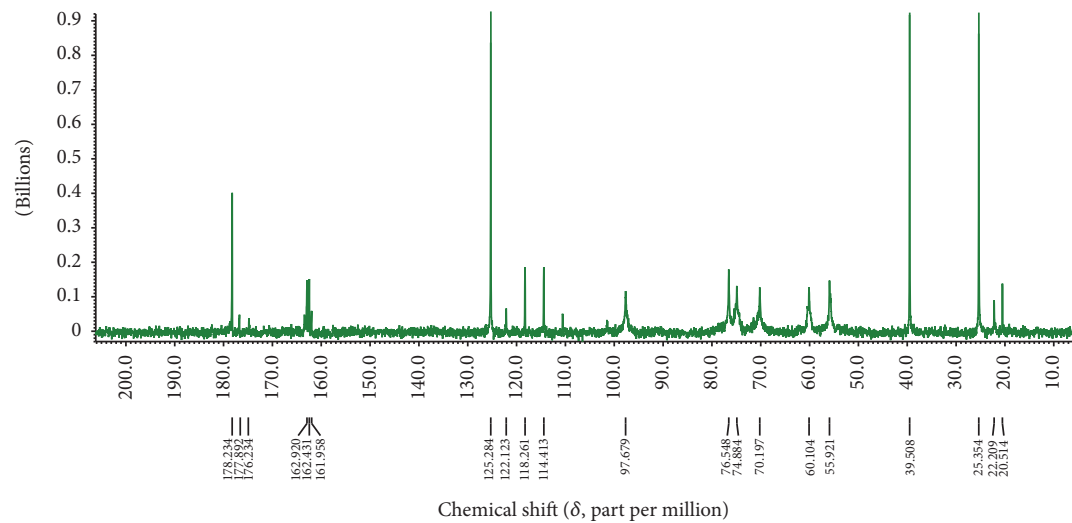

(c)

Figure 2: ${ }^{1} \mathrm{H}$-NMR spectra of chitosan (a) and $\mathrm{N}$-(6-carboxyl cyclohex-3-ene carbonyl) chitosan (5) and ${ }^{13} \mathrm{C}$-NMR of product 5 (c) in $1 \%$ $\mathrm{CF}_{3} \mathrm{COOD} / \mathrm{D}_{2} \mathrm{O}$ at $25^{\circ} \mathrm{C}$.

acyl group of $\mathrm{N}$-(6-carboxyl cyclohex-3-ene carbonyl) moiety and that was found in the acetyl group of chitosan structure (Figure 2(c)). Strong and intense peaks at 25.35, 39.50, and $125.28 \mathrm{ppm}$ were obtained due to the presence of carbon atoms in the $N$-(6-carboxyl cyclohex-3-ene carbonyl) moiety.

The result of solubility of the chitosan and $N$-(6-carboxyl cyclohex-3-ene carbonyl) chitosans (1-5) is shown in Table 2. The data shows that the derivatives were more soluble than chitosan in water and diluted aqueous acetic acid solutions. In addition, the derivatives became soluble also in alkaline basic medium (sodium hydroxide solution) indicating the presence of the carboxyl group in the product [33].

3.2. Antibacterial Activity of Chitosan Derivatives. The in vitro antibacterial activities of chitosan and $N$-(6-carboxyl cyclohex-3-ene carbonyl) chitosans against E. carotovora, $R$. solanacearum, $R$. fascians, and $R$. radiobacter are presented in Table 3 as MIC. The results proved that the 
TABLE 2: Solubility of chitosan and $N$-(6-carboxyl cyclohex-3-ene carbonyl) chitosan derivatives.

\begin{tabular}{lccccc}
\hline Compound & Distilled water & $\begin{array}{c}\text { Solubility } \\
\text { acid (0.1\%) }\end{array}$ & $\begin{array}{c}\text { Aqueous acetic } \\
\text { acid (0.5\%) }\end{array}$ & $\begin{array}{c}\text { Aqueous acetic } \\
\text { acid (1\%) }\end{array}$ & $\begin{array}{c}\text { Aqueous sodium } \\
\text { hydroxide (1\%) }\end{array}$ \\
\hline Chitosan & Insoluble & Gel & Soluble & Soluble & Insoluble \\
1 & Swelling & Gel & Soluble & Soluble & Soluble \\
2 & Swelling & Gel & Soluble & Soluble & Soluble \\
3 & Gel & Soluble & Soluble & Soluble & Soluble \\
4 & Gel & Soluble & Soluble & Soluble & Soluble \\
5 & Gel & Soluble & Soluble & Soluble & \\
\hline
\end{tabular}

TABle 3: Antibacterial activity of chitosan and $N$-(6-carboxyl cyclohex-3-ene carbonyl) chitosan derivatives against E. carotovora, $R$. solanacearum, $R$. fascians, and $R$. radiobacter by broth microdilution technique.

\begin{tabular}{lcccc}
\hline Chitosan product & & \multicolumn{2}{c}{ MIC $^{\mathrm{a}}(\mathrm{mg} / \mathrm{L})$} & R. fascians \\
\hline Chitosan & E. carotovora & R. solanacearum & 1100 & \\
1 & 1050 & 1880 & 585 & \\
2 & 755 & 1125 & 480 & \\
3 & 690 & 1045 & 330 & 515 \\
4 & 640 & 945 & 255 & 460 \\
5 & 590 & 810 & 240 & 310 \\
\hline
\end{tabular}

${ }^{\mathrm{a}} \mathrm{MIC}$ is a minimum inhibitory concentration. MIC is the lowest concentration of an antimicrobial that will inhibit the visible growth of a microorganism after overnight incubation.

derivatives showed higher inhibition (MIC ranged from 240 to $1125 \mathrm{mg} / \mathrm{L}$ ) than chitosan (MIC ranged from 1050 to $1880 \mathrm{mg} / \mathrm{L}$ ) against all the tested bacteria. The data indicated that the inhibitory effects increased with the DS increase and the most inhibition effect was observed with compound 5 (DS $=0.40$ ) with MIC of $510,735,240$, and $385 \mathrm{mg} / \mathrm{L}$ against $E$. carotovora, R. solanacearum, R. fascians, and R. radiobacter, respectively.

Recently, the antibacterial activity of $\mathrm{N}$-(4-carboxybutyroyl) chitosan derivatives at different DS values $(0.10,0.25$, 0.48 and 0.53 ) was evaluated against Agrobacterium tumefaciens and E. carotovora. They reported that the compound of DS 0.53 was the most active one (MIC $=725$ and $800 \mathrm{mg} / \mathrm{L}$ against E. carotovora and A. tumefaciens, resp.) [33]. Previous studies on the antibacterial activity of $N, N, N$-dimethylalkyl chitosans as water-soluble derivatives and $N$-(benzyl) chitosan derivatives was done under the same conditions as the present study against E. carotovora and A. tumefaciens $[41,45]$.

3.3. Antifungal Activity of Chitosan Derivatives. The antifungal activity of chitosan and $N$-(6-carboxyl cyclohex-3ene carbonyl) chitosan derivatives against $A$. alternata, $B$. cinerea, Bd. theobromae, F. oxysporum, F. solani, P. digitatum, $P h$. infestans, and $S$. sclerotiorum by using mycelia radial growth technique is presented in Table 4 . The native chitosan molecule in the present study has low activity against the tested pathogens. Conversely, $\mathrm{N}$-(6-carboxyl cyclohex-3-ene carbonyl) chitosan derivatives appeared to be synergistic, and a marked increase in antifungal activity was noted. Unmodified chitosan showed $\mathrm{EC}_{50}$ higher than $3000 \mathrm{mg} / \mathrm{L}$ against
B. cinerea, $B d$. theobromae, $P$. digitatum, and S. sclerotiorum. However, a notable effect was exerted against $A$. alternata, $F$. oxysporum, F. solani, and P. infestans with $\mathrm{EC}_{50}$ of 2849, 2697, 1848 , and $1600 \mathrm{mg} / \mathrm{L}$, respectively. The derivatives were more active than chitosan and the inhibition effect was increased significantly with the DS increase. Compound 5 with a DS 0.40 exerted the prominent antifungal activity with $\mathrm{EC}_{50}$ of $683,774,501,500,260,417,298$, and $763 \mathrm{mg} / \mathrm{L}$ against $A$. alternata, B. cinerea, Bd. theobromae, F. oxysporum, F. solani, $P$. digitatum, $P h$. infestans, and S. sclerotiorum, respectively. However, compound 1 with the lowest DS (0.09) was the lowest active one with $\mathrm{EC}_{50}$ of $1390,1560,971,1338,641,1645$, 511 , and $1746 \mathrm{mg} / \mathrm{L}$, respectively. In regard to the susceptibility of the eight tested fungi, it can be noticed that the fungi of $F$. solani and $P h$. infestans were more susceptible $\left(\mathrm{EC}_{50}\right.$ ranged from 260 to $641 \mathrm{mg} / \mathrm{L}$ ) to these derivatives than the other tested fungi.

The present study noticed that the antifungal activity was increased dramatically with an increase in DS and MW values. This phenomenon is in agreement with Zhong and others who reported that the amount of grafted acetyl phenyl-thiosemicarbazone in the acetyl and benzoyl phenylthiosemicarbazone derivatives of chitosan correlated with the antifungal activity of the derivatives [46, 47]. Jia and coauthors found that pyridine chitosan exhibited enhanced antifungal activity by comparison with pristine chitosan [48]. The values of the MIC and the minimal fungicidal concentration of pyridine chitosan against B. cinerea were 130 and $4000 \mathrm{mg} / \mathrm{L}$, respectively. Severe morphological changes of pyridine chitosan-treated $B$. cinerea were observed, indicative of the fact that pyridine chitosan could damage and deform 


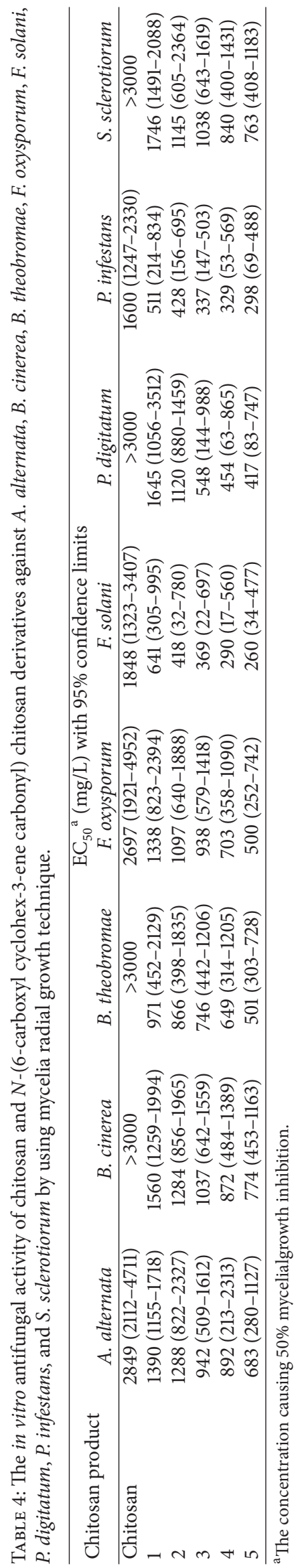


the structure of fungal hyphae and subsequently inhibit strain growth. The antifungal activities of chitosan derivatives (1,2diaminoethaneanhydrous, butylamine, and pyridine) were significantly increased against Rhizoctonia cerealis, F. oxysporum, and $B$. cinerea and the inhibition rate ranged from 22.48 to $63.56 \%$ [20]. In the bioassay of F. oxysporum and $P$. debaryanum, $N$-(benzyl) chitosan derivatives exhibited high inhibition percentage of spore germination at $1000 \mathrm{mg} / \mathrm{L} \mathrm{[45].}$

Previous study with water-soluble $N$-(4-carboxybutyroyl) chitosan derivatives with different DS reported that the highest DS 0.53 exerted the highest antifungal activity against B. cinerea, $P$. debaryanum, and $R$. solani $\left(\mathrm{EC}_{50}=899,467\right.$, and $1413 \mathrm{mg} / \mathrm{L}$, resp.) [33]. However, compound 1 with a MW of $3.78 \times 10^{5} \mathrm{~g} / \mathrm{mol}$ and DS 0.10 was the lowest active one with $\mathrm{EC}_{50}$ of 2170,814 , and $2395 \mathrm{mg} / \mathrm{L}$ against $B$. cinerea, $P$. debaryanum, and $R$. solani, respectively. Other derivatives include $N$-(cinnamyl), $N$-(cuminyl), and $N$-( $p$ dimethylaminobenzyl) chitosan proved moderately antifungal activity, and the $\mathrm{EC}_{50}$ values were 1520, 1673, and $1786 \mathrm{mg} / \mathrm{L}$, respectively, against B. cinerea [17]. O-(Phenoxyacetic) chitosans were more potent as antifungal activity than chitosan and $O$-(o,p-dichlorophenoxyacetic) chitosan was the highest in its mycelial growth inhibition with $\mathrm{EC}_{50}$ of $1084,715,1216,1417,638$, and $1285 \mathrm{mg} / \mathrm{L}$ against $A$. alternata, $B d$. theobromae, F. oxysporum, F. solani, $P$. infestans, and $P$. debaryanum, respectively [49]. N,O-( $p$-Chlorobutyryl) chitosan, $\mathrm{N}, \mathrm{O}$-decanoyl chitosan, $\mathrm{N}, \mathrm{O}$-cinnamoyl chitosan, and $\mathrm{N}, \mathrm{O}$-( $p$-methoxybenzoyl) chitosan were the most potent ones within eighteen derivatives of $\mathrm{N}, \mathrm{O}$-acyl chitosans [24] against $B$. cinerea $\left(\mathrm{EC}_{50}=430,440,450\right.$, and $500 \mathrm{mg} / \mathrm{L}$, resp. $)$ and were 12 - to 13 -fold more active than chitosan. However, $\mathrm{N}$ (benzo[d][1,3]dioxol-5-ylmethyl) chitosan and $N$-(methyl$4 \mathrm{H}$-chromen-4-one) chitosan were the most active within five heterocyclic chitosan derivatives against $P$. debaryanum and F. oxysporum [18].

The most antifungal mechanism of chitosan is that the positively charged chitosan gives this one great physiological and biological polymer property. It consumes electronegative charges on the surface of the microbial cells resulting in change in cell wall permeability, so that the interaction results in leakage of electrolytes, intracellular protein components, and the disturbance of the plasma membrane [21, 50, 51]. In addition, chitosan caused a decrease in the $\mathrm{H}^{+}$-ATPase activity on plasma membrane of $R$. stolonifer; this effect could provoke the accumulation of protons inside the cell, which would result in the inhibition of the chemiosmotic driven transport that allows the $\mathrm{H}^{+} / \mathrm{K}^{+}$exchange [52]. Another important mechanism on fungi stated that the chitosan enters fungal cells and then adsorbs essential nutrients, which inhibit or retard the synthesis of mRNA and protein [53]. Chitosan also acts as a chelating agent that selectively binds trace metals and thus inhibits toxin production and microbial growth [54].

\section{Conclusion}

The antimicrobial activity is one of the most important bioactivities of chitosan and it will be improved in some of the derivatives, which is determined by the groups grafted to chitosan. In the present study, $N$-(6-carboxyl cyclohex-3ene carbonyl) chitosans with five DS values were synthesized and tested against some plant pathogens. The products at the tested concentrations exhibited a wide range of the antibacterial and antifungal activity in vitro. It was observed that the highest DS value is more active than the lowest one. Therefore, we can suggest that such products could be used in plant protection program for controlling the plant pathogens that cause destruction of the crops and vegetables. However, formulating of such compounds is essential for commercial uses of the pesticidal chitosan products with further in vivo studies being essentially needed. Such formulations can be used in organic and conventional agricultural systems if the formulations are improved for foliar application.

\section{Competing Interests}

The authors declare that there is no conflict of interests regarding the publication of this paper.

\section{References}

[1] C. K. S. Pillai, W. Paul, and C. P. Sharma, "Chitin and chitosan polymers: chemistry, solubility and fiber formation," Progress in Polymer Science, vol. 34, no. 7, pp. 641-678, 2009.

[2] P. K. Dutta, J. Duta, and V. S. Tripathi, "Chitin and Chitosan: chemistry, properties and applications," Journal of Scientific and Industrial Research, vol. 63, no. 1, pp. 20-31, 2004.

[3] R. A. A. Muzzarelli, Chitin, Elsevier, New York, NY, USA, 2013.

[4] S. Chandrkrachang, "The application of chitin and chitosan in agriculture in Thailand," Advances in Chitin Science, vol. 5, pp. 458-462, 2002.

[5] E. I. Rabea, M. E.-T. Badawy, C. V. Stevens, G. Smagghe, and W. Steurbaut, "Chitosan as antimicrobial agent: applications and mode of action," Biomacromolecules, vol. 4, no. 6, pp. 1457-1465, 2003.

[6] M. E. I. Badawy and E. I. Rabea, "A biopolymer chitosan and its derivatives as promising antimicrobial agents against plant pathogens and their applications in crop protection," International Journal of Carbohydrate Chemistry, vol. 2011, Article ID 460381, 29 pages, 2011.

[7] F. Shahidi, J. K. V. Arachchi, and Y.-J. Jeon, "Food applications of chitin and chitosans," Trends in Food Science \& Technology, vol. 10, no. 2, pp. 37-51, 1999.

[8] Q. Liu, C. Wu, H. Cai, N. Hu, J. Zhou, and P. Wang, "Cell-based biosensors and their application in biomedicine," Chemical Reviews, vol. 114, no. 12, pp. 6423-6461, 2014.

[9] M. Kumar, D. McGlade, and J. Lawler, "Functionalized chitosan derived novel positively charged organic-inorganic hybrid ultrafiltration membranes for protein separation," RSC Advances, vol. 4, no. 42, pp. 21699-21711, 2014.

[10] B. Krajewska, "Application of chitin- and chitosan-based materials for enzyme immobilizations: a review," Enzyme and Microbial Technology, vol. 35, no. 2-3, pp. 126-139, 2004.

[11] K. Xing, X. Zhu, X. Peng, and S. Qin, "Chitosan antimicrobial and eliciting properties for pest control in agriculture: a review," Agronomy for Sustainable Development, vol. 35, no. 2, pp. 569588, 2015. 
[12] A. El Hadrami, L. R. Adam, I. El Hadrami, and F. Daayf, "Chitosan in plant protection," Marine Drugs, vol. 8, no. 4, pp. 968-987, 2010.

[13] I. M. Helander, E.-L. Nurmiaho-Lassila, R. Ahvenainen, J. Rhoades, and S. Roller, "Chitosan disrupts the barrier properties of the outer membrane of Gram-negative bacteria," International Journal of Food Microbiology, vol. 71, no. 2-3, pp. 235-244, 2001.

[14] N. R. Sudarshan, D. G. Hoover, and D. Knorr, "Antibacterial action of chitosan," Food Biotechnology, vol. 6, no. 3, pp. 257272, 1992.

[15] R. C. Goy, S. T. B. Morais, and O. B. G. Assis, "Evaluation of the antimicrobial activity of chitosan and its quaternized derivative on E. Coli and S. aureus growth," Brazilian Journal of Pharmacognosy, vol. 26, no. 1, pp. 122-127, 2016.

[16] N. M. Alves and J. F. Mano, "Chitosan derivatives obtained by chemical modifications for biomedical and environmental applications," International Journal of Biological Macromolecules, vol. 43, no. 5, pp. 401-414, 2008.

[17] M. E. I. Badawy and E. I. Rabea, "Synthesis and antifungal property of $N$-(aryl) and quaternary $N$-(aryl) chitosan derivatives against Botrytis cinerea," Cellulose, vol. 21, no. 4, pp. 3121-3137, 2014.

[18] M. El Badawy, "Chemical modification of chitosan: synthesis and biological activity of new heterocyclic chitosan derivatives," Polymer International, vol. 57, no. 2, pp. 254-261, 2008.

[19] R. Jayakumar, M. Prabaharan, R. L. Reis, and J. F. Mano, "Graft copolymerized chitosan-present status and applications," Carbohydrate Polymers, vol. 62, no. 2, pp. 142-158, 2005.

[20] H.-C. Ge and D.-K. Luo, "Preparation of carboxymethyl chitosan in aqueous solution under microwave irradiation," Carbohydrate Research, vol. 340, no. 7, pp. 1351-1356, 2005.

[21] H. Sashiwa, N. Kawasaki, A. Nakayama et al., "Chemical modification of chitosan. Part 15: synthesis of novel chitosan derivatives by substitution of hydrophilic amine using $N$-carboxyethylchitosan ethyl ester as an intermediate," Carbohydrate Research, vol. 338, no. 6, pp. 557-561, 2003.

[22] E. I. Rabea, M. E. I. Badawy, T. M. Rogge et al., "Enhancement of fungicidal and insecticidal activity by reductive alkylation of chitosan," Pest Management Science, vol. 62, no. 9, pp. 890-897, 2006.

[23] R. de Oliveira Pedro, C. C. Schmitt, and M. G. Neumann, "Syntheses and characterization of amphiphilic quaternary ammonium chitosan derivatives," Carbohydrate Polymers, vol. 147, pp. 97-103, 2016.

[24] M. E. I. Badawy, E. I. Rabea, T. M. Rogge et al., "Synthesis and fungicidal activity of new N,O-acyl chitosan derivatives," Biomacromolecules, vol. 5, no. 2, pp. 589-595, 2004.

[25] S. Hirano, Y. Ohe, and H. Ono, "Selective $N$-acylation of chitosan," Carbohydrate Research, vol. 47, no. 2, pp. 315-320, 1976.

[26] M. Shibano, S. Nishida, Y. Saito, H. Kamitakahara, and T. Takano, "Facile synthesis of acyl chitosan isothiocyanates and their application to porphyrin-appended chitosan derivative," Carbohydrate Polymers, vol. 113, pp. 279-285, 2014.

[27] T. Satoh, L. Vladimirov, M. Johmen, and N. Sakairi, "Preparation and thermal dehydration of $N$-(carboxy)acyl chitosan derivatives with high stereoregularity," Chemistry Letters, vol. 32, no. 4, pp. 318-319, 2003.

[28] R. Yamaguchi, Y. Arai, T. Itoh, and S. Hirano, "Preparation of partially N-succinylated chitosans and their cross-linked gels," Carbohydrate Research, vol. 88, no. 1, pp. 172-175, 1981.
[29] H. Sashiwa, Y. Shigemasa, and R. Roy, "Homogeneous N,Oacylation of chitosan in dimethyl sulfoxide with cyclic acid anhydrides," Chemistry Letters, no. 10, pp. 1186-1187, 2000.

[30] S. Hirano, M. Zhang, B. G. Chung, and S. K. Kim, " $N$-acylation of chitosan fibre and the $N$-deacetylation of chitin fibre and chitin-cellulose blended fibre at a solid state," Carbohydrate Polymers, vol. 41, no. 2, pp. 175-179, 2000.

[31] S. Hirano and T. Moriyasu, "N-(carboxyacyl)chitosans," Carbohydrate Research, vol. 92, no. 2, pp. 323-327, 1981.

[32] S. Hirano, Y. Yamaguchi, and M. Kamiya, "Novel N-saturatedfatty-acyl derivatives of chitosan soluble in water and in aqueous acid and alkaline solutions," Carbohydrate Polymers, vol. 48, no. 2, pp. 203-207, 2002.

[33] M. E. I. Badawy and E. I. Rabea, "Characterization and antimicrobial activity of water-soluble N-(4-carboxybutyroyl) chitosans against some plant pathogenic bacteria and fungi," Carbohydrate Polymers, vol. 87, no. 1, pp. 250-256, 2012.

[34] G. G. Allan and M. Peyron, "Molecular weight manipulation of chitosan II: prediction and control of extent of depolymerization by nitrous acid," Carbohydrate Research, vol. 277, no. 2, pp. 273-282, 1995.

[35] G. G. Allan and M. Peyron, "Molecular weight manipulation of chitosan I: kinetics of depolymerization by nitrous acid," Carbohydrate Research, vol. 277, no. 2, pp. 257-272, 1995.

[36] P. J. Flory, Principles of Polymer Chemistry, Cornell University Press, 1953.

[37] C. Tanford, Physical Chemistry of Macromolecules, John Wiley \& Sons, New York, NY, USA, 1961.

[38] M. Sugimoto, M. Morimoto, H. Sashiwa, H. Saimoto, and Y. Shigemasa, "Preparation and characterization of water-soluble chitin and chitosan derivatives," Carbohydrate Polymers, vol. 36, no. 1, pp. 49-59, 1998.

[39] J. N. Eloff, "A sensitive and quick microplate method to determine the minimal inhibitory concentration of plant extracts for bacteria," Planta Medica, vol. 64, no. 8, pp. 711-713, 1998.

[40] D. M. Yajko, J. J. Madej, M. V. Lancaster et al., "Colorimetric method for determining MICs of antimicrobial agents for Mycobacterium tuberculosis," Journal of Clinical Microbiology, vol. 33, no. 9, pp. 2324-2327, 1995.

[41] M. E. I. Badawy, E. I. Rabea, and N. E. M. Taktak, "Antimicrobial and inhibitory enzyme activity of $N$-(benzyl) and quaternary $N$-(benzyl) chitosan derivatives on plant pathogens," Carbohydrate Polymers, vol. 111, pp. 670-682, 2014.

[42] D. J. Finney, Probit Analysis, Cambridge University Press, 3rd edition, 1971.

[43] A. Hirai, H. Odani, and A. Nakajima, "Determination of degree of deacetylation of chitosan by $1 \mathrm{H}$ NMR spectroscopy," Polymer Bulletin, vol. 26, no. 1, pp. 87-94, 1991.

[44] H. Sashiwa and Y. Shigemasa, "Chemical modification of chitin and chitosan 2: preparation and water soluble property of $N$-acylated or $N$-alkylated partially deacetylated chitins," Carbohydrate Polymers, vol. 39, no. 2, pp. 127-138, 1999.

[45] E. I. Rabea, M. E. I. Badawy, W. Steurbaut, and C. V. Stevens, "In vitro assessment of $\mathrm{N}$-(benzyl)chitosan derivatives against some plant pathogenic bacteria and fungi," European Polymer Journal, vol. 45, no. 1, pp. 237-245, 2009.

[46] Z. Zhong, B. Aotegen, H. Xu, and S. Zhao, "Structure and antimicrobial activities of benzoyl phenyl-thiosemicarbazonechitosans," International Journal of Biological Macromolecules, vol. 50, no. 4, pp. 1169-1174, 2012. 
[47] Z. Zhong, B. Aotegen, H. Xu, and S. Zhao, "The influence of chemical structure on the antimicrobial activities of thiosemicarbazone-chitosan," Cellulose, vol. 21, no. 1, pp. 105114, 2014.

[48] R. Jia, Y. Duan, Q. Fang, X. Wang, and J. Huang, "Pyridinegrafted chitosan derivative as an antifungal agent," Food Chemistry, vol. 196, pp. 381-387, 2016.

[49] E. I. Rabea, "In vitro assessment of antimicrobial property of O-(phenoxyacetic) chitosan compounds on plant pathogens," Journal of Chitin and Chitosan Science, vol. 2, no. 4, pp. 293-298, 2014.

[50] Z. Guo, R. Xing, S. Liu et al., "The influence of molecular weight of quaternized chitosan on antifungal activity," Carbohydrate Polymers, vol. 71, no. 4, pp. 694-697, 2008.

[51] A. El Ghaouth, J. Arul, A. Asselin, and N. Benhamou, "Antifungal activity of chitosan on post-harvest pathogens: induction of morphological and cytological alterations in Rhizopus stolonifer," Mycological Research, vol. 96, no. 9, pp. 769-779, 1992.

[52] J. García-Rincón, J. Vega-Pérez, M. G. Guerra-Sánchez, A. N. Hernández-Lauzardo, A. Peña-Díaz, and M. G. Velázquez-Del Valle, "Effect of chitosan on growth and plasma membrane properties of Rhizopus stolonifer (Ehrenb.:Fr.) Vuill," Pesticide Biochemistry and Physiology, vol. 97, no. 3, pp. 275-278, 2010.

[53] M. R. Avadi, A. M. M. Sadeghi, A. Tahzibi et al., "Diethylmethyl chitosan as an antimicrobial agent: synthesis, characterization and antibacterial effects," European Polymer Journal, vol. 40, no. 7, pp. 1355-1361, 2004.

[54] R. G. Cuero, G. Osuji, and A. Washington, "N-carboxymethylchitosan inhibition of aflatoxin production: role of zinc," Biotechnology Letters, vol. 13, no. 6, pp. 441-444, 1991. 

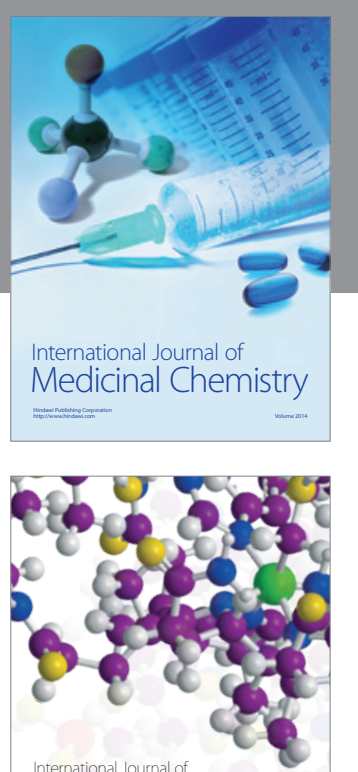

Carbohydrate Chemistry

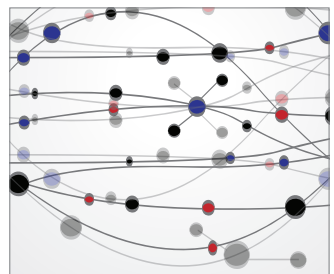

The Scientific World Journal
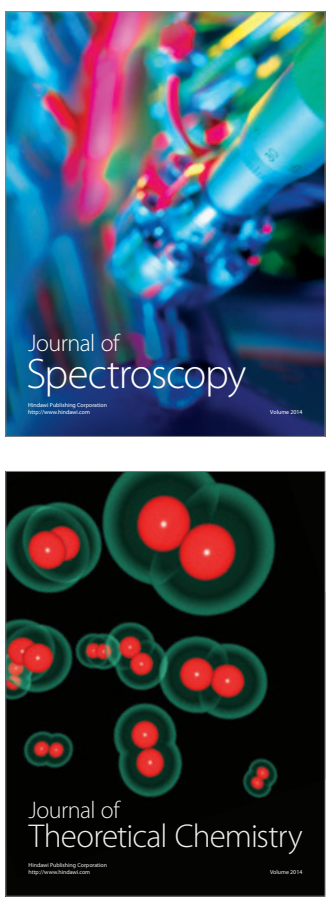
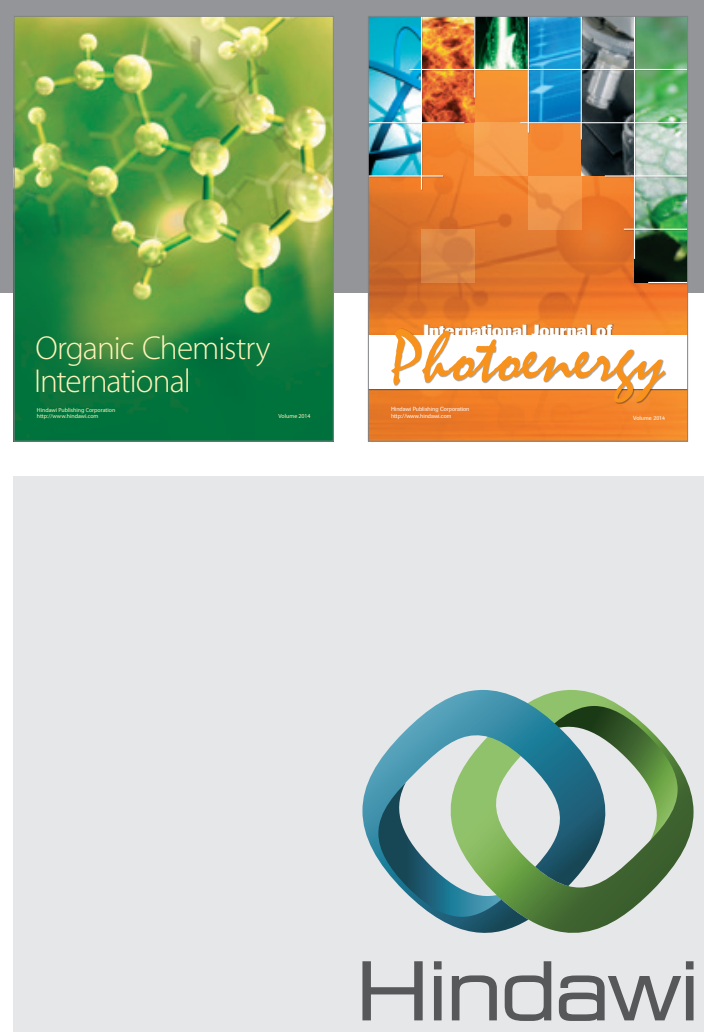

Submit your manuscripts at

http://www.hindawi.com

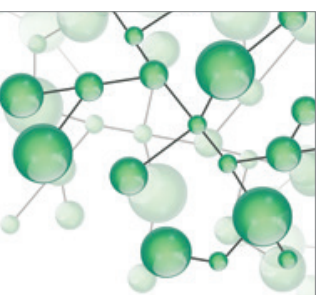

International Journal of

Inorganic Chemistry

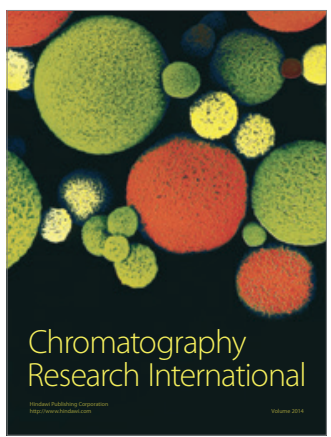

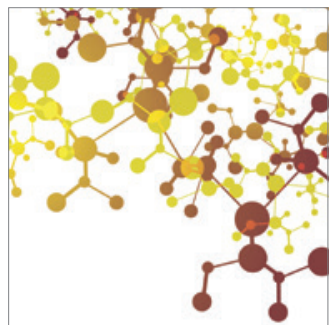

Applied Chemistry
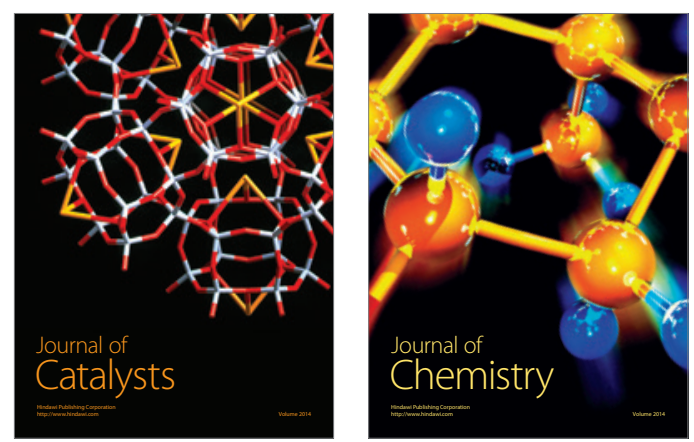
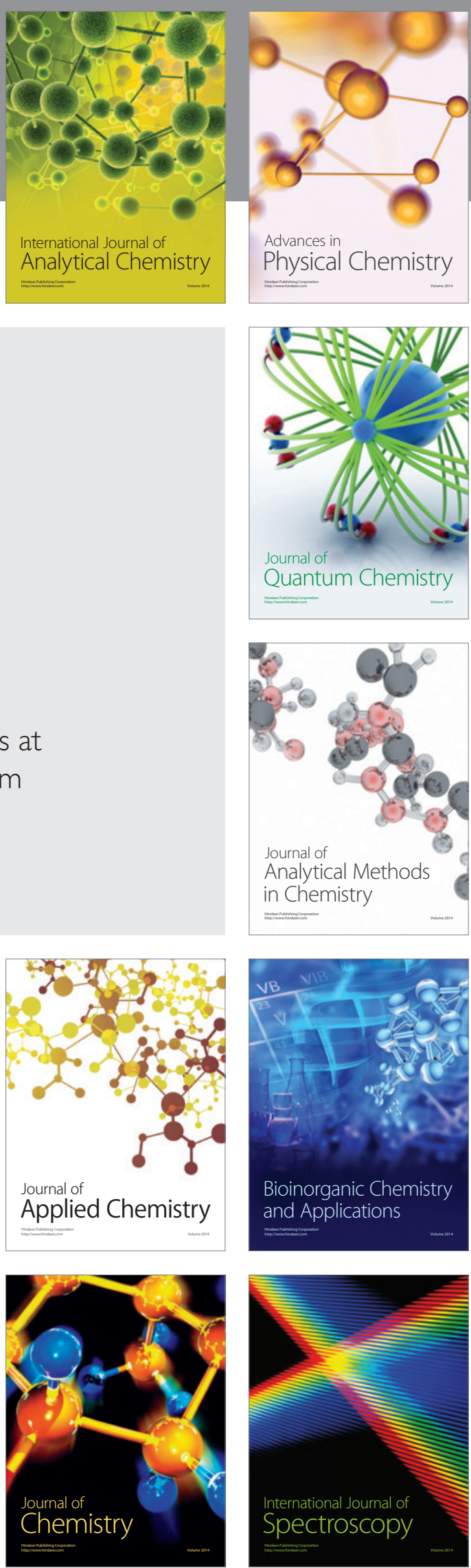